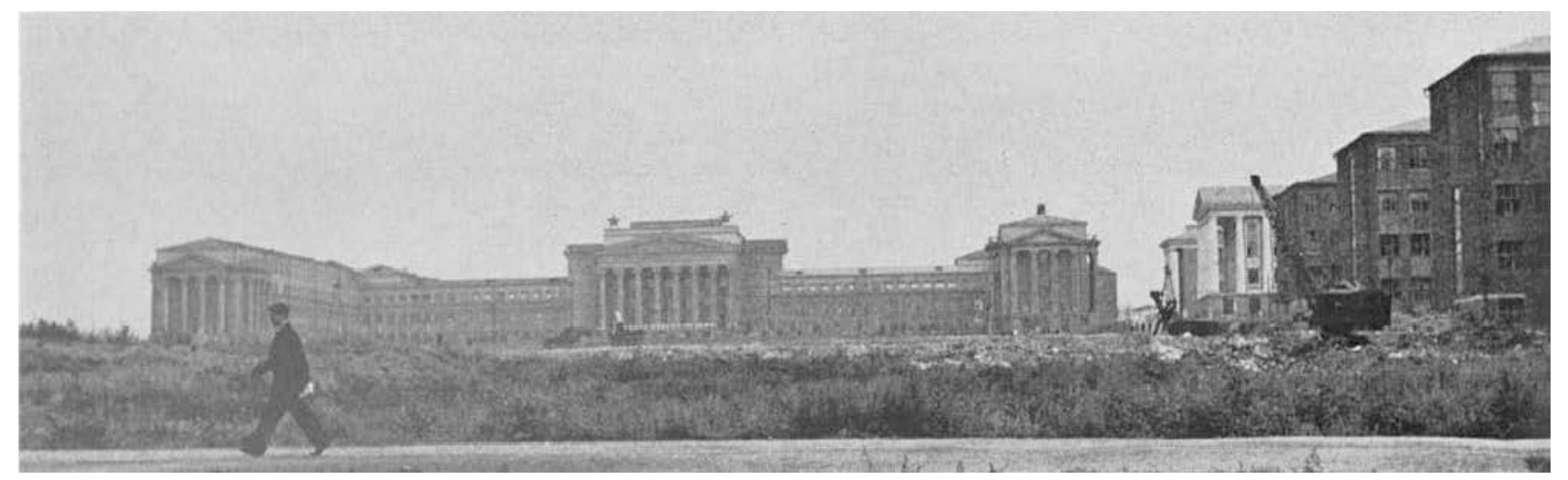

Sverdlovsk Polytechnic Institute has 15,000 students of which 1000 are in metallurgy. The curriculum is similar to that of the Leningrad Institute. The metallurgy department includes laboratories for resecrch in iron, steelmaking, casting, rolling, ore treatment, non-ferrous metals, phose diagrams, kinetics, and analytical chemistry.

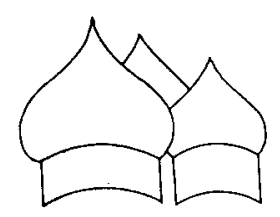

\title{
Quantity and Quality in Russian Metallurgical Education
}

\author{
For further comments on Russian metallurgical education we turned to \\ Walter R. Hibbard, Jr., \\ Manager of Alloy Studies at the General Electric Research Laboratory.
}

In the institutes and colleges in the USSR most students study free of charge, and the State pays the entire cost plus a stipend. For students at the Moscow Steel Institute, the stipend is 400 rubles per month in the first year and some additional rubles per month for each ensuing year. It was said that this stipend is more than the average income per person in Russia, since 800 to 900 rubles per month is the average income per family, and four persons is the average family size; hence, the average income is from 200 to 225 rubles per person. Studying certainly seems to be a paying thing in the USSR, and apparently young men and women are aware of this, since there are several times as many students applying for entrance to in-technical colleges and institutes as are accepted.

The size of the educational effort in metallurgy is quite impressive. By simply totaling the number of metallurgical graduates from the five institutes visited, it comes to about 2000 to 3000 per year. This is approximately four to five times the number of metallurgists which are graduated in the US. These graduates have had a five or five and one half year course, which appears to be approximately equal to the average metallurgical course in the US. One first wonders how they can absorb this large number of metallurgists into a metals industry which is smaller than that of the US. Actually, they may use these metallurgists for many jobs which would not require metallurgists in the US, or else they may put a large number of people on a given job, possibly without regard for economics, but solely with regard to the effects on production.

The educational courses appear to be intensive, requiring hard work and a rather strong financial and career incentive. The professors and teaching staff with whom I came in contact appeared to be quite familiar with existing knowledge in their subject and in particular with the published literature of all countries.

The educational facilities, in so far as equipment was concerned, were approximately equivalent to the average facilities in an American university, but the buildings were worn and in need of repair. The classes were small, usually involving groups from 6 to 25 , particularly in the last two years. The educational institutions all engaged in some research, but it appears that much of this was descriptive. 